\title{
Water-resistant Lewis-acid sites: carbonyl-ene reactions catalyzed by tin-containing, hydrophobic molecular sieves
}

\author{
Avelino Corma* and Michael Renz* \\ Instituto de Tecnología Química, UPV-CSIC, Avda. los Naranjos, 46022 Valencia, Spain \\ E-mail: acorma@itq.upv.es, mrenz@itq.upv.es
}

\begin{abstract}
Two solid Lewis acids, namely Sn-Beta and Sn-MCM-41, have been applied to the CarbonylEne reaction of $\beta$-pinene and $\alpha$-methylstyrene with paraformaldehyde. For the more bulky molecule $\beta$-pinene the mesoporous material Sn-MCM-41 has been found to be the better catalyst whereas for the smaller $\alpha$-methylstyrene Sn-Beta has shown a higher activity. Best selectivities have been observed in nitrile solvents, such as acetonitrile and butyronitrile, whereas reactions in toluene or dioxane have been less selective. The catalysts are water resistant what has been evidenced by addition of up to $200 \mathrm{wt} \%$ (with respect to the catalyst) of water without loss of activity or selectivity. Sn-MCM-41 has been employed in several cycles with intermediate regeneration, always recovering the high activity.
\end{abstract}

Keywords: Nopol, paraformaldehyde, Sn-Beta, Sn-MCM-41, solid Lewis acid

\section{Introduction}

Nopyl acetate (4) is an artificial fragrance compound with a fresh-fruity-woody odour. ${ }^{1}$ In industry it is prepared by a Carbonyl-Ene reaction of $\beta$-pinene (1) and paraformaldehyde (2) with subsequent acetylation of the intermediary nopol (3) with acetic anhydride (Scheme 1).

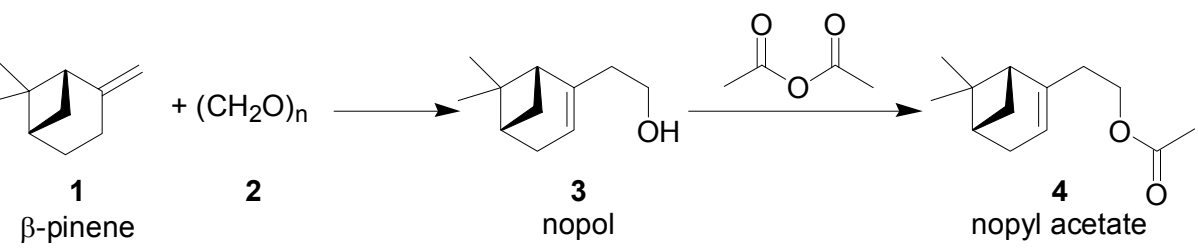

Scheme 1. Industrial process for the production of nopyl acetate (4) from $\beta$-pinene (1)

The conversion of olefin 1 with paraformaldehyde (2) into alcohol $\mathbf{3}$ has been achieved thermally in an autoclave at $150-230^{\circ} \mathrm{C}$ or in presence of catalytic quantities of a homogeneous 
catalyst such as $\mathrm{ZnCl}_{2}$ at $115-120^{\circ} \mathrm{C} .^{2}$ Very recently, heterogeneous Lewis acidic catalysts have been applied to the carbonyl-Ene reaction step. Mesoporous iron phosphate has been found to be active for this reaction ${ }^{3}$ as well as mesoporous MCM-41 or Sn grafted on MCM-41 ${ }^{4}$. However, in most cases a big amount of catalyst was necessary being this an important drawback with respect to a potential industrial application. For instance, for complete transformation within $4 \mathrm{~h} 150 \mathrm{wt} \%$ of iron phosphate have been employed, or $74 \mathrm{wt} \%$ of catalyst for a $82 \%$ conversion after $6 \mathrm{~h}$. Also in the case of MCM-41 a high catalyst amount was used (150 wt $\%$ ) that could be decreased significantly to $35 \mathrm{wt} \%$ by the incorporation of $\mathrm{Sn}$. This incorporation of tin has been done by chemical vapour deposition (CVD) of $\mathrm{SnCl}_{4}$ with subsequent calcination. Using this catalyst and in the three additional cycles with recycled catalyst, almost $250 \mathrm{mg}$ of $\beta$-pinene (1) have been converted into alcohol 3 with $25 \mathrm{mg}$ of catalyst. In the final Sn-MCM-41 catalyst, a 4 : 1 molar ratio of chlorine to tin has been measured and therefore, it is suggested that the tin is grafted as $\mathrm{SnCl}_{4}$, being uniformly distributed without forming clusters.

At present, we are working with Lewis acid catalysts involving tin atoms incorporated into siliceous matrices. For instance, we have incorporated tin into Beta zeolite and the resulting material could be applied for the Baeyer-Villiger oxidation ${ }^{5,6}$ and the Meerwein-Ponndorf-Verley reduction. ${ }^{7,8}$ In this material, tin is not bound to any electron-withdrawing chlorine but either to four framework silyloxy groups forming a tetrahedral $(\mathrm{OSi})_{4} \mathrm{Sn}$ centre or, with one of these $\mathrm{Sn}$ O-Si hydrolyzed, resulting in a $(\mathrm{SiO})_{3} \mathrm{Sn}(\mathrm{OH})$ centre. ${ }^{9}$ For more bulky substrates tin has been incorporated directly into the wall of MCM-41 during the synthesis of the molecular sieve. ${ }^{10,11}$ The advantage over the above mentioned material is that from the preparation sequence of the catalyst (synthesis, CVD, calcination) one step is eliminated since the metal is already introduced during the synthesis step and CVD is not required.

Sn-Beta has been applied to an intramolecular version of the carbonyl-Ene reaction, namely to the cyclization of citronellal to isopulegol. ${ }^{12}$ This is also an industrially essential step in the menthol synthesis. Herein, we want to report on the application of Sn-Beta and Sn-MCM41 to the intermolecular carbonyl-Ene reaction between $\beta$-pinene or $\alpha$-methylstyrene with paraformaldehyde.

\section{Results and Discussion}

Tin has been incorporated by direct synthesis into zeolite Beta and mesoporous MCM-41. First, 50-mg samples of Sn-MCM-41 (0.8, 3.6, and $4.4 \mathrm{mg}$ of Sn; 6.74, 30.3, and $37.1 \mu \mathrm{mol}$, respectively) were submitted to a reaction mixture of $600 \mathrm{mg}(4.41 \mathrm{mmol})$ of olefin $1,300 \mathrm{mg}$ (2.2 equiv.) of paraformaldehyde (2) and $3.0 \mathrm{~g}$ of toluene. In Table 1 it can be seen that, when $1.6 \mathrm{wt} \%$ of tin were incorporated into the mesoporous material, $444 \mathrm{mg}$ (3.26 mmol) of $\beta$-pinene (1) were converted into alcohol 3 with $50 \mathrm{mg}$ of Sn-MCM-41 (6.74 $\mu \mathrm{mol}$ of Sn; Table 1, entry 1). In other words we have achieved in one cycle using the Sn-MCM-41 catalyst practically the same number of moles per mg of catalyst as obtained with the CVD material prepared with 
$\mathrm{SnCl}_{4}$ in four cycles. Therefore, activity measured by the turnover number (TON), i.e. mol of substrate converted per mol of tin, indicated a much higher activity of the Sn-MCM-41 produced by direct synthesis. More specifically the TON for this catalyst in one cycle was 483 whereas with the CVD material a number of 152 has been summed over the four cycles. The selectivity of $79 \%$ for the Sn-MCM-41 from direct synthesis was very similar to the one achieved with the CVD catalyst in the first cycle $(80 \%)$. The total reaction time was shortened from $26 \mathrm{~h}(\mathrm{CVD})$ to only $2 \mathrm{~h}$ (direct synthesis).

Sn-Beta possesses a higher intrinsic activity than Sn-MCM-41 for molecules that can diffuse within the micropores without geometrical restraints. ${ }^{11,13}$ However, in the present case Sn-Beta was a less successful catalyst for the transformation of olefin $\mathbf{1}$ into alcohol $\mathbf{3}$. The conversion decreased to only $63 \%$, a clearly lower value than the $94 \%$ achieved with Sn-MCM41 (Table 1, entries 7 and 1, respectively). The effect was even more pronounced when one considered that for Sn-Beta a lower substrate to catalyst ratio was employed (260 instead of 650 $[\mathrm{mol} / \mathrm{mol}])$. Probably, the bulky molecules of the bicyclic $\beta$-pinene (1) have difficulties for the diffusion within the narrow channels of the Beta zeolite $(6.5-7.6 \AA) .{ }^{14}$ This has been observed before and, in these cases Sn-MCM-41 could improve the catalytic performance by increasing the rate of reactant diffusion. ${ }^{11,13}$

Table 1. Conversions and selectivities towards alcohol $\mathbf{3}$ in the presence of different catalysts

\begin{tabular}{|c|c|c|c|c|c|c|c|c|c|}
\hline \multirow[b]{2}{*}{ Entry } & \multirow[b]{2}{*}{ Catalyst } & \multirow[b]{2}{*}{$\begin{array}{c}\mathrm{Sn}^{\mathrm{b}} \\
{[\mathrm{wt} \%]}\end{array}$} & \multirow[b]{2}{*}{$\begin{array}{l}\text { Time } \\
{[\mathrm{h}]}\end{array}$} & \multirow[b]{2}{*}{$\begin{array}{c}\text { Conv. } \\
{[\%]}\end{array}$} & \multicolumn{5}{|c|}{ Product selectivity $^{\mathrm{a}}$} \\
\hline & & & & & $\begin{array}{c}3^{\mathrm{c}} \\
{[\%]}\end{array}$ & $\begin{array}{c}\alpha-\text { Pin. }^{\mathrm{d}} \\
{[\%]}\end{array}$ & $\begin{array}{c}\text { Camph. }^{\mathrm{e}} \\
{[\%]}\end{array}$ & $\begin{array}{c}\text { Lim. }^{f} \\
{[\%]}\end{array}$ & $\begin{array}{c}\text { Other }^{\mathrm{g}} \\
{[\%]}\end{array}$ \\
\hline 1 & Sn-MCM-41 & $1.6(650)$ & 2 & 94 & 79 & 2 & 4 & 4 & 11 \\
\hline 2 & Sn-MCM-41 & $7.2(155)$ & 0.5 & 93 & 70 & 1 & 3 & 4 & 22 \\
\hline 3 & Sn-MCM-41 & $8.8(121)$ & 1 & 98 & 69 & 4 & 5 & 7 & 15 \\
\hline 4 & Al-MCM-41 & $\mathrm{h}$ & 0.25 & 99 & 11 & 4 & 11 & 19 & 55 \\
\hline 5 & Ti-MCM-41 & $\mathrm{i}$ & 2 & 8 & 18 & 12 & 18 & 21 & 31 \\
\hline 6 & all-silica MCM-41 & 0 & 2 & 11 & 56 & 5 & 6 & 8 & 25 \\
\hline 7 & Sn-Beta ${ }^{j}$ & $2.0(260)$ & 2 & 63 & 77 & 3 & 5 & 1 & 14 \\
\hline
\end{tabular}

${ }^{a}$ determined by GC chromatography on the crude reaction mixture; experimental error $5 \%$ of the stated values. ${ }^{b}$ weight percent of tin with respect to the total catalyst weight; in parentheses substrate/tin ratio [mol/mol]. ${ }^{\mathrm{c}}$ selectivity to the desired product nopol. ${ }^{\mathrm{d}}$ selectivity to $\alpha$-pinene. ${ }^{\mathrm{e}}$ selectivity to camphene. ${ }^{\mathrm{f}}$ selectivity to limonene. ${ }^{\mathrm{g}}$ selectivity to other unidentified products. ${ }^{\mathrm{h}}$ $1.7 \mathrm{wt} \%$ of Al. ${ }^{\mathrm{i}} 7.2 \mathrm{wt} \%$ of $\mathrm{Ti}^{\mathrm{j}}{ }^{\mathrm{j}}$ with $300 \mathrm{mg}$ of substrate instead of $600 \mathrm{mg}$.

It was possible to incorporate more $\mathrm{Sn}$ into the MCM-41 material and the reaction time could be shortened further, but a decrease in product selectivity occurred. Alcohol $\mathbf{3}$ was only observed in 70 or $69 \%$ selectivity (Table 1, entries 2 and 3). A very low amount of the desired product was observed when the type of active sites is changed to Lewis acid Ti sites. These type 
of sites were unreactive and gave alcohol 3 only with $18 \%$ selectivity (Table 1, entry 5). Brönsted acid sites as generated in Al-MCM-41 converted olefin 1 completely within only 15 min, however, the desired product was only obtained in $11 \%$ yield (Table 1, entry 4) being the formation of camphene, limonene and $\alpha$-pinene main reactions occuring on this catalyst. The parent system, i.e. all silica MCM-41, had only low catalytic activity. Only 11\% of olefin 1 was converted and the selectivity towards the desired product was low (Table 1, entry 6). In this case, the catalytic activity was probably due to the presence of silanol groups which act as weak Brönsted acid sites.

When the substrate/catalyst ratio was varied it could be observed that there is only a small decrease in conversion from 99 to $96 \%$ for ratios of 60 to $241(\mathrm{~mol} / \mathrm{mol})$ and the selectivity remained almost unchanged. Consequently, the amount of $\beta$-pinene converted into nopol (3) in the presence of Sn-MCM-41 could be improved to $840 \mathrm{mg}(6.17 \mathrm{mmol})$ per $50 \mathrm{mg}$ of catalyst or $4.4 \mathrm{mg}(37.1 \mu \mathrm{mol})$ of Sn (Table 2, entry 3$)$. When only 1.1 equiv. of paraformaldehyde was employed, both conversion and selectivity decreased significantly (Table 2, entry 4).

Table 2. Conversions and selectivities towards alcohol $\mathbf{3}$ for different substrate/catalyst ratios (Sn-MCM-41 with $8.8 \mathrm{wt} \%$ of $\mathrm{Sn}, 60 \mathrm{~min}$ reaction time)

\begin{tabular}{cccccccc}
\hline & & & \multicolumn{4}{c}{ Product selectivity $^{\mathrm{a}}$} \\
\cline { 4 - 8 } Entry & $\begin{array}{c}\text { Substrate/tin ratio } \\
{[\mathrm{mol} / \mathrm{mol}]}\end{array}$ & $\begin{array}{c}\text { Conv } \\
{[\%]}\end{array}$ & $\begin{array}{c}\mathbf{3}^{\mathrm{b}} \\
{[\%]}\end{array}$ & $\alpha$-Pinene & $\begin{array}{c}\text { Camphene } \\
{[\%]}\end{array}$ & $\begin{array}{c}\text { Limonene } \\
{[\%]}\end{array}$ & Other $^{\mathrm{c}}$ \\
\hline 1 & 60 & 99 & 73 & 1 & 3 & 3 & $20]$ \\
2 & 121 & 98 & 69 & 4 & 5 & 7 & 15 \\
3 & 241 & 96 & 72 & 1 & 2 & 2 & 23 \\
4 & $121^{\mathrm{d}}$ & 86 & 67 & 2 & 4 & 4 & 23 \\
\hline
\end{tabular}

${ }^{a}$ Determined by GC chromatography on the crude reaction mixture; experimental error $5 \%$ of the stated values. ${ }^{b}$ selectivity to the desired product nopol. ${ }^{c}$ selectivity to other unidentified products. ${ }^{\mathrm{d}}$ only 1.1 equiv. of paraformaldehyde were employed instead of 2.2.

The formation of side products and the decrease of selectivity was attributed to isomerization side-reactions caused by acidic sites. When this type of side reaction was observed during the Ti-Beta catalyzed epoxidation of olefins the selectivity could be much improved by employing acetonitrile as solvent. ${ }^{15}$ It has been supposed that the weakly basic acetonitrile molecules neutralize these acid sites. Therefore, in the present reaction acetonitrile was used as solvent to improve the product selectivity towards the desired product. Indeed, this was slightly improved from $73 \%$ to $84 \%$ although at the expenses of conversion (Table 3, entry 1). Only 13\% of the substrate had been converted after $2 \mathrm{~h}$ reaction time versus more than $90 \%$ in toluene as solvent (cf. Table 1). The low conversion was improved by changing to a nitrile with a higher boiling point and working at higher reaction temperature. Thus, raising the temperature to $90{ }^{\circ} \mathrm{C}$ and using butyronitrile as solvent, $65 \%$ of the substrate was converted after $6 \mathrm{~h}$ reaction time 
with $92 \%$ selectivity (Table 3 , entry 2 ). Almost complete conversion was achieved at reaction temperatures of 100 and $110^{\circ} \mathrm{C}$ and after $8 \mathrm{~h}$ reaction time (cf. Table 3, entries 3 and 6) being the selectivity 90 and 94\%, respectively. For comparison purposes all-silica MCM-41 was used as catalyst and it was confirmed that under the present conditions this material was not an effective catalyst (cf. Table 3, entry 7).

Table 3. Conversions and selectivities towards alcohol 3 in nitrile solvents with Sn-MCM-41 $(7.2 \mathrm{wt} \% \mathrm{Sn})$ as catalyst

\begin{tabular}{cccccc}
\hline Entry & Solvent & $\begin{array}{c}\text { Temp. } \\
{\left[{ }^{\circ} \mathrm{C}\right]}\end{array}$ & $\begin{array}{c}\text { Time } \\
{[\mathrm{h}]}\end{array}$ & $\begin{array}{c}\text { Conv. } \\
{[\%]}\end{array}$ & $\begin{array}{c}\text { Selectivity to } \mathbf{3}^{\mathrm{a}} \\
{[\%]}\end{array}$ \\
\hline 1 & $\mathrm{MeCN}$ & 80 & 2 & 13 & 84 \\
2 & $n-\mathrm{PrCN}$ & 90 & 6 & 65 & 92 \\
3 & $n-\mathrm{PrCN}^{\mathrm{w}}$ & 100 & 8 & 93 & 90 \\
4 & $n-\mathrm{PrCN}^{\mathrm{b}}$ & 100 & 8 & 37 & 90 \\
5 & $n-\mathrm{PrCN}^{\mathrm{c}}$ & 100 & 8 & 91 & 90 \\
6 & $n-\mathrm{PrCN}^{\mathrm{d}}$ & 110 & 8 & 93 & 94 \\
7 & $n-\mathrm{PrCN}^{\mathrm{d}}$ & 100 & 8 & 21 & 6 \\
\hline
\end{tabular}

${ }^{a}$ Determined by GC-chromatography on the crude product mixture; experimental error $5 \%$ of the stated value. ${ }^{b}$ Catalyst re-used from entry 3 without any treatment. ${ }^{c} 400 \mathrm{mg}$ of formaldehyde were used instead of $300 \mathrm{mg} .{ }^{\mathrm{d}} \mathrm{Si}-\mathrm{MCM}-41$ was used as catalyst.

A unique characteristic of the tin-containing molecular sieves is the stability against water. When the carbonyl-Ene reaction is carried out in presence of the homogeneous Lewis acid $\mathrm{BF}_{3} \cdot \mathrm{OEt}_{2}$, water has to be trapped efficiently by molecular sieves to guarantee high yields of ene products. ${ }^{16}$ In contrast, the present system allowed the addition of water up to, at best, $200 \mathrm{wt} \%$ with respect to the catalyst without any penalty on conversion and selectivity (cf. Table 4).

Table 4. Conversions and selectivities towards alcohol 3 with Sn-MCM-41 (7.2\% Sn) as catalyst in the presence of water (butyronitrile solvent at $100^{\circ} \mathrm{C}$ and after $8 \mathrm{~h}$ reaction time)

\begin{tabular}{cccc}
\hline Entry & $\begin{array}{c}{\left[\mathrm{H}_{2} \mathrm{O}\right]} \\
{[\mathrm{mg}]}\end{array}$ & $\begin{array}{c}\text { Conv. } \\
{[\%]}\end{array}$ & $\begin{array}{c}\text { Selectivity to } \mathbf{3}^{\mathbf{a}} \\
{[\%]}\end{array}$ \\
\hline 1 & 0 & 93 & 90 \\
2 & 48 & 91 & 93 \\
3 & 81 & 94 & 92 \\
4 & 118 & 95 & 92 \\
\hline
\end{tabular}

${ }^{a}$ Determined by GC-chromatography on the crude product mixture; experimental error $5 \%$ of the stated value. 
One of the advantages of heterogeneous catalysts is the easy separation from the reaction mixture by filtration and the possibility of recycling the catalyst. When Sn-MCM-41 was filtered out and submitted to a fresh reaction mixture without any regeneration treatment, the catalyst was still active and selective (cf. Table 3, entries 3 and 4). However, after recycling the conversion was less than $50 \%$ of the original one. Nevertheless, the initial activity can be recovered by calcination. Thus, regeneration in an air-flow at $540{ }^{\circ} \mathrm{C}$ for $3 \mathrm{~h}$ allowed to recover the full activity (cf. Table 5, entries 1 and 2). In subsequent cycles the conversion dropped 510\% (Table 5, entries 3 and 4), but activity was still high.

In summary, $\mathrm{Sn}$ Lewis acid sites incorporated into a siliceous matrices resulted in active and selective catalysts for the Carbonyl-Ene reaction. The mesoporous support allowed diffusion without sterical restrictions and this material was more active than the best heterogeneous catalysts reported up to now for the synthesis of nopol (3). The activity was maintained in several subsequent runs with intermediate regeneration steps and it retained its activity and selectivity in the presence of water in the reaction mixture.

Table 5. Conversions and selectivities towards alcohol 3 with Sn-MCM-41 (7.2 wt\% Sn) as catalyst in the several cycles with intermediary activation by calcination (400 $\mathrm{mg}$ of paraformaldehyde, burtyronitrile as solvent at $100{ }^{\circ} \mathrm{C}$ and after $8 \mathrm{~h}$ reaction time)

\begin{tabular}{cccc}
\hline Entry & Cycle & $\begin{array}{c}\text { Conv. } \\
{[\%]}\end{array}$ & $\begin{array}{c}\text { Selectivity to } \mathbf{3}^{\mathrm{a}} \\
{[\%]}\end{array}$ \\
\hline 1 & 1 & 93 & 94 \\
2 & 2 & 93 & 93 \\
3 & 3 & 85 & 94 \\
4 & 4 & 83 & 93 \\
\hline
\end{tabular}

${ }^{a}$ Determined by GC-chromatography on the crude product mixture; experimental error $5 \%$ of the stated value.

When the Sn-molecular sieve catalysts presented here for the carbonyl-Ene reaction with formaldehyde were tested for a smaller substrate, such as $\alpha$-methylstyrene (5; Scheme 2), 3phenylbut-3-en-1-ol (6) was obtained with toluene as solvent (Table 6, entries 1 and 4), but selectivity towards the homoallylic alcohol 6 was low, e.g. $31 \%$ in the case of Sn-MCM-41. Selectivity could be much improved by changing the solvent from toluene to 1,4-dioxane or acetonitrile. In this case, $81 \%$ conversion and $90 \%$ selectivity were obtained in the presence of Sn-Beta (Table 6, entry 6). This result confirms that the low activity of Sn-Beta in the nopol reaction was not due to a lower intrinsic activity for the Carbonyl-Ene reaction with paraformaldehyde but to the geometric restriction of the zeolite channels. 


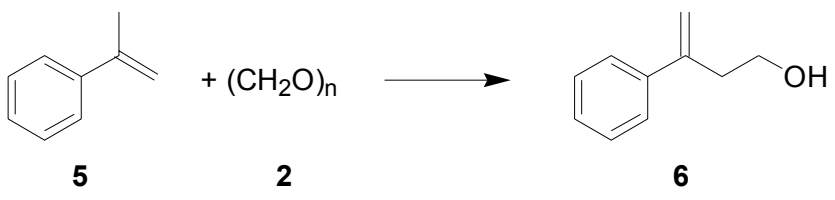

Scheme 2

When this result was compared to others reported in the literature it can be concluded that a catalyst in where Sn was incorporated within the structure of micro- and mesoporous molecular sieves, i.e. Sn-Beta and Sn-MCM-41 presented a significant catalytic improvement with respect to the previously reported catalysts. Indeed, $\mathrm{BF}_{3}$ was used before as promoter in the presence of zeolite 4 A to guarantee anhydrous conditions. ${ }^{16}$ In general $100 \mathrm{wt} \%$ of the zeolite was employed and more than stoichiometric amounts (1.2 equiv.) of the Lewis acid. Although the conditions worked well for 3,4-dichloro- $\alpha$-methylstyrene and the corresponding product was obtained in $72 \%$ yield, the yield dropped for $\alpha$-methylstyrene (5) to only $41 \%$.

In an earlier approach metal cation exchanged montmorrillonite was employed as heterogeneous catalyst. ${ }^{17}$ Thereby, $\alpha$-methylstyrene ( 1 equiv.) and paraformaldehyde ( 2 equiv.) were dissolved in acetonitrile and reacted for $24 \mathrm{~h}$ at $80{ }^{\circ} \mathrm{C}$ reaction temperature in the presence of $58 \mathrm{wt} \%$ of $\mathrm{Zr}^{4+}$-montmorrillonite ( $5 \mathrm{~mol} \%$ of metal). Alcohol 6 was obtained in $61 \%$ yield in $80 \%$ selectivity. The TON was calculated as 12 per acid site of $\mathrm{Zr}^{4+}$-montmorillonite measured by temperature-programmed desorption of ammonia gas $\left(\mathrm{NH}_{3}-\mathrm{TPD}\right)$ method. For the best tin case (Sn-Beta, acetonitrile, Table 6, entry 6) a TON of 440 has been achieved here, that was more than one order of magnitude better than $\mathrm{Zr}^{4+}$-montmorrillonite.

Table 6. Conversions and selectivities towards alcohol 6 for the carbonyl-Ene reaction of $\alpha$ methylstyrene (5) with paraformaldehyde in the presence of Sn-Beta and Sn-MCM-41 in different solvent (Reaction time $2 \mathrm{~h}$, reaction temperature $90^{\circ} \mathrm{C}$ )

\begin{tabular}{cccccc}
\hline Entry & Catalyst & $\begin{array}{c}\text { Sn } \\
{[\mathrm{wt} \%]}\end{array}$ & Solvent & $\begin{array}{c}\text { Conv. } \\
{[\%]}\end{array}$ & $\begin{array}{c}\text { Selectivity to 6 } \\
{[\%]}\end{array}$ \\
\hline 1 & Sn-MCM-41 & 7.2 & toluene & 70 & 31 \\
2 & Sn-MCM-41 & 7.2 & dioxane & 61 & 73 \\
3 & Sn-MCM-41 & 7.2 & acetonitrile & 26 & 95 \\
4 & Sn-Beta & 2.0 & toluene & 72 & 61 \\
5 & Sn-Beta & 2.0 & dioxane & 35 & 88 \\
6 & Sn-Beta & 2.0 & acetonitrile $^{\mathrm{b}}$ & 81 & 90 \\
\hline
\end{tabular}

${ }^{a}$ Determined by GC-chromatography on the crude product mixture; experimental error $5 \%$ of the stated value. ${ }^{\mathrm{b}}$ reaction temperature $80{ }^{\circ} \mathrm{C}$. 


\section{Experimental Section}

General Procedures. All substrates and solvents were purchased from Aldrich or Acros and used without any further purification. GC analyses were carried out by means of a HP 5890 gas chromatograph equipped with a 25 m HP-5 column. GC-MS analyses for the identification of products were carried out on an Agilent Technologies 6890N apparatus coupled with an Agilent Mass Selective Detector 5973 Network. ${ }^{1} \mathrm{H}$ NMR spectra were recorded with a Bruker spectrometer at a frequency of $300 \mathrm{MHz}$.

Synthesis of the molecular sieves. Sn-Beta was synthesized according to literature procedure. $^{16,18}$ The Sn-Beta zeolite was calcined at $853 \mathrm{~K}$ for $3 \mathrm{~h}$. A high crystallinity of the zeolite was observed by XRD, and no peaks of $\mathrm{SnO}_{2}$ were found in the diffractogram. Nitrogen adsorption experiments on the calcined Beta samples gave an isotherm very similar to that of pure silica Beta with values of micropore volume of $0.20-0.21 \mathrm{~cm}^{3} \mathrm{~g}^{-1}$ and BET surface areas of $450-475 \mathrm{~m}^{2} \mathrm{~g}^{-1}$. The Sn content $(2.0 \mathrm{wt} \%)$ was determined by atomic absorption analysis.

The Sn-MCM-41 samples were synthesized according the following procedure: ${ }^{10}$ An aqueous solution of hexadecyltrimethylammonium hydroxide $\left(\mathrm{C}_{16} \mathrm{TAOH}\right)$ was mixed with a tetramethylammonium hydroxide solution $(25 \%$, Aldrich) and an aqueous solution of $\mathrm{SnCl}_{4} .5 \mathrm{H}_{2} \mathrm{O}$ (98\%, Aldrich). After homogenisation, the silica (Aerosil, Degussa) was added under continuous stirring. The final composition was the following: $1 \mathrm{SiO}_{2}:(0.16-\mathrm{x}) \mathrm{C}_{16} \mathrm{TABr}$ : $4 \mathrm{x} \mathrm{C}_{16} \mathrm{TAOH}: 0.26 \mathrm{TMAOH}: \mathrm{x} \mathrm{SnCl}_{4}: 24.3 \mathrm{H}_{2} \mathrm{O}$, where $\mathrm{x}$ was varied between 0.01 and 0.04 . The homogeneous gel was sealed in Teflon-lined stainless steel autoclaves and heated at $135^{\circ} \mathrm{C}$ under static conditions during 24 hours. The resulting solid product was recovered by filtration, washed and dried at $60{ }^{\circ} \mathrm{C}$ for 24 hours. The occluded organic was removed by heating the solid at $813 \mathrm{~K}$ for 1 hour in a flow of $\mathrm{N}_{2}$, followed by 6 hours in air. The solid obtained presents a typical XRD pattern of MCM-41 structure. The Sn contents (1.6, 7.2 and $8.8 \mathrm{wt} \%)$ were determined by atomic absorption.

General procedure for the carbonyl-Ene reaction for the nopol (3) formation. Olefin 1 (600 $\mathrm{mg}, 4.41 \mathrm{mmol}$ ), paraformaldehyde ( $300 \mathrm{mg}, 2.2$ equiv.), $3.0 \mathrm{~g}$ of toluene and a $50-\mathrm{mg}$ sample of the catalyst were stirred magnetically and heated to $90{ }^{\circ} \mathrm{C}$ reaction temperature. The reaction was followed by gas chromatography, and the products were identified by GC-MS and nopol (3) characterized by NMR spectroscopy. Additionally, the identity of $\alpha$-pinene, camphene, and limonene was confirmed by GC analysis of the authentic samples.

To assure a complete mass balance, in one case (Table 5, entry 2) the crude product mixture was isolated. To do this, the catalyst was collected by filtration and the solvent distilled off. The crude product was obtained in $85 \%$ yield and contained more than $90 \%$ of the desired nopol. The product was identified by ${ }^{1} \mathrm{H}$ NMR spectroscopy. ${ }^{19}$ The solvent recovered contained $3 \%$ of substrate and $3 \%$ of nopol.

${ }^{1} \mathrm{H} \mathrm{NMR}\left(\mathrm{CDCl}_{3}, 300 \mathrm{MHz}\right): \delta=0.84(\mathrm{~s}, 3 \mathrm{H}), 1.14(\mathrm{~d}, J=8.6 \mathrm{~Hz}, 1 \mathrm{H}), 1.27(\mathrm{~s}, 3 \mathrm{H}), 1.68$ (brs, $1 \mathrm{H}), 2.03(\mathrm{dt}, J=0.96,5.1 \mathrm{~Hz}, 1 \mathrm{H}), 2.10(\mathrm{~m}, 1 \mathrm{H}), 2.23(\mathrm{~m}, 4 \mathrm{H}), 2.37(\mathrm{~m}, 1 \mathrm{H}), 3.60(\mathrm{t}, J=6.0$ $\mathrm{Hz}, 2 \mathrm{H}), 5.34$ (brs, $1 \mathrm{H}$ ). 
General procedure for the carbonyl-Ene reaction with $\alpha$-methylstyrene (5) and paraformaldehyde. Olefin 5 (600 mg, $5.08 \mathrm{mmol})$, paraformaldehyde (300 mg, 2 equiv.), $3.0 \mathrm{~g}$ of solvent and a 50-mg sample of the catalyst were stirred magnetically and heated to $90{ }^{\circ} \mathrm{C}$ reaction temperature $\left(80{ }^{\circ} \mathrm{C}\right.$ in the case of acetonitrile). The reaction was followed by gas chromatography, and the products were identified by GC-MS spectroscopy.

\section{Acknowledgements}

The authors thank CICYT (MAT-2006-3798164), for financing this work. M. R. is grateful to the Spanish Ministry of Science and Technology for a "Ramón y Cajal" Fellowship.

\section{References and Notes}

1. Bauer, K.; Garbe, D.; Suburg, H. Common Fragrance and Flavor Materials, Wiley-VCH: Weinheim, 1997; p 69f.

2. Bain, J. P. J. Am. Chem. Soc. 1946, 638.

3. Pillai, U. R.; Sahle-Demessie, E. Chem. Commun. 2004, 826.

4. Villa de P., A. L. ; Alarcon, E. ; Montes de Correa, C. Chem. Commun. 2002, 2654.

5. Corma, A.; Nemeth, L. T.; Renz, M.; Valencia, S. Nature 2001, 412, 423.

6. Renz, M.; Blasco, T.; Corma, A.; Fornés, V.; Jensen, R.; Nemeth, L. Chem. Eur. J. 2002, 8, 4708.

7. Corma, A.; Domine, M. E.; Nemeth, L. T.; Valencia, S. J. Am. Chem. Soc. 2002, 124, 3194.

8. Corma, A.; Domine, M. E.; Valencia, S. J. Catal. 2003, 215, 294.

9. Boronat, M.; Concepcion, P.; Corma, A.; Renz, M.; Valencia, S. J. Catal. 2005, 234, 111.

10. Corma, A.; Navarro, M. T.; Nemeth, L.; Renz, M. Chem. Commun. 2001, 2190.

11. Corma, A.; Iborra, S.; Mifsud, M.; Renz, M. J. Catal. 2005, 234, 96.

12. Corma, A.; Renz, M. Chem. Commun. 2004, 550.

13. Corma, A.; Iborra, S.; Mifsud, M.; Renz, M. Arkivoc 2005, (9) ME-1342H; http://www.arkivoc.org/ARKIVOC/JOURNAL_CONTENT/manuscripts/2005/ME1342HP\%20as\%20published\%20mainmanuscript.pdf.

14. For a similar case of restricted reactivity for the pinene molecule in the Beta zeolite pores see isomerization of $\alpha$-pinene over Beta zeolites: Gündüz, G.; Dimitrova, R.; Yilmaz, S.; Dimitrov, L.; Spassova, M. J. Mol. Catal. A: Chem. 2005, 225, 253.

15. Corma, A.; Esteve, P.; Martínez, A. J. Catal. 1996, 161, 11.

16. Okachi, T.; Fujimoto, K.; Onaka, M. Org. Lett. 2002, 4, 1667.

17. Tateiwa, J.; Kimura, A.; Takasuka, M.; Uemura, S. J. Chem. Soc., Perkin Trans. 1 1997, 2167.

18. Valencia, S.; Corma, A. US Patent 5968473 (assigned to UOP), 1999.

19. Miyazawa, M.; Suzuki, Y.; Kameoka, H. Phytochemistry 1995, 39, 337. 